\title{
ESTRATÉGIAS DE MARKETING DIGITAL NAS MÍDIAS SOCIAIS COMO FERRAMENTAS DE APROXIMAÇÃO ENTRE CLIENTE E EMPRESA
}

\section{ARTIGO ORIGINAL}

SOUSA, Dyllmar Alves de ${ }^{1}$

SILVA, Karina da ${ }^{2}$

FARIAS, Clenio Ferreira de ${ }^{3}$

GALVÃO, Maria Edenilda da Silva ${ }^{4}$

SANTOS, Gislaine de Souza dos ${ }^{5}$

1 Mestrando em Administração de empresas, pela Universidad Autónoma de Asunción, Especialista em Gestão e Estratégias de Marketing pela Faculdade Internacional Signorelli e Bacharel em Administração pela Faculdade Adelmar Rosado.

2 Mestranda em Administração pela Universidade Autônoma de Assunção, Pósgraduada em Contabilidade Fiscal e Tributária pela Faculdade Católica de Rondônia; Bacharel em Ciências Contábeis pela Fundação Universidade Federal de Rondônia. ${ }^{3}$ Mestrando em Administração pela Universidade Autônoma de Assunção, Pósgraduado em Contabilidade, Perícia e Auditoria pela Universidade Norte do Paraná.

${ }^{4}$ Mestrando em Administração pela Universidade Autônoma de Assunção, Pósgraduada em matemática e física pela Universidade do Sul de Santa Catarina, Licenciada pela Universidade Federal do Amazonas.

${ }^{5}$ Mestranda em Administração de Empresas pela Universidad Autónoma de Asunción. Pós-Graduada em Gestão de Pessoas pela Universidade Candido Mendes, UCAM, Brasil. Graduada em Administração de Empresas pela Universidade Federal de Rondônia, UNIR, Brasil. 
MENDES, Maria de Fátima ${ }^{6}$

SANTOS, Sônia do Socorro ${ }^{7}$

SOUSA, Dyllmar Alves de. Et al. Estratégias de marketing digital nas mídias sociais como ferramentas de aproximação entre cliente e empresa. Revista Científica Multidisciplinar Núcleo do Conhecimento. Ano 04, Ed. 11, Vol. 03, pp. 128145. Novembro de 2019. ISSN: 2448-0959, Link de acesso: https://www.nucleodoconhecimento.com.br/marketing/marketing-digital

\section{RESUMO}

Este estudo teve por objetivo analisar as estratégias de marketing digital nas mídias sociais como forma de aproximação entre clientes e empresa. Foram avaliadas duas estratégias de marketing digital utilizadas por duas empresas de supermercado, denominadas por A e B. A pesquisa procedeu-se inicialmente com a revisão bibliográfica exploratória e, posteriormente, realizou-se um estudo comparativo, sendo fundamentado por pesquisa descritiva com abordagem qualitativa e quantitativa. Os dados foram coletados nas mídias e plataforma Fanpage Karma por um período de 15 dias. Avaliou-se ainda, a estratégia de marketing em mídia social e de conteúdo. Conclui-se que a empresa $B$ posta maior parte dos seus conteúdos nas mídias sociais com intenção inteiramente relacional e institucional, sendo a referida empresa a que

\footnotetext{
${ }^{6}$ Mestranda em Administração de Empresas pela Universidad Autónoma de Asunción. Pós-graduada em Contabilidade Avançada e Controladoria pela Faculdade de Ciências Biomédicas de Cacoal, FACIMED, Brasil. Graduada em Ciências Contábeis pela UNESC- União das Escolas Superiores de Cacoal, UNESC, Brasil.

${ }^{7}$ Mestranda em Administratión De Empresas pela Universidad Autónoma de Asunción - Paraguay. Pós-Graduada em MBA Em Formação Avançada De Consultores E Executivos Em Gestão Financeira, Auditoria E Controladoria, pela Faculdade Estratego em Belém do Pará.
} 
apresentou maior número de usuários, e também maior aproximação com seus clientes.

Palavras-chave: Marketing Digital, mídia social, clientes.

\section{INTRODUÇÃO}

Mudanças nos modelos econômicos através do tempo deixaram como legado o mercado digital e, paralelo aos padrões comportamentais, refletiu-se nos consumidores, nas empresas e no relacionamento entre ambos, abrindo o caminho para uma nova maneira de marketing que é o marketing digital (BOGO; $\mathrm{KLOCH}$, 2012).

Falar em marketing digital é pensar num mundo virtual onde aumenta cada vez mais o número de usuários e os benefícios que tal ferramenta pode trazer para uma empresa, o mesmo vem alcançando audiência refinada em um ambiente que ainda não está saturado pela concorrência (CINTRA, 2010).

Desta forma, o mercado que não acompanha a expansão da internet, ou não utiliza esta ferramenta, que é o marketing digital, pode estar perdendo clientes em potenciais, uma vez que com o mundo cada vez mais informatizado as oportunidades de expor uma marca, ou mercadoria aumentaram consideravelmente sua visibilidade.

Segundo Barichello e Oliveira (2010), o acesso livre à internet, principalmente no mundo de informações presentes nas redes e mídias sociais, fez com que os consumidores ficassem mais exigentes e participativos e, para esse novo consumidor, as empresas estão criando estratégias cada vez mais interativas no intuito de conquistar sua atenção.

Nesse sentido, o domínio de estratégias de marketing digital tem ajudado efetivamente as empresas na fidelização de clientes. Os convívios com as mais diversas formas de mídias sociais e o acompanhamento do seu desenvolvimento têm despertado interesse no sentido de investigar tais mecanismos de comunicação, além de procurar entender às suas funcionalidades no marketing digital, e dessa forma, 
procurar tirar um maior proveito dessa ferramenta que a cada dia tem estado mais presente na vida dos consumidores.

A presente pesquisa teve como objetivo geral descrever as ações utilizadas de marketing digital nas mídias sociais através dos indicadores de desempenho em função da aproximação entre cliente e empresa. Os objetivos específicos deste estudo foram: identificar as mídias sociais utilizadas pelas empresas, determinar indicadores para análise de desempenho e avaliar o marketing de conteúdo através das publicações nas redes sociais.

A presente pesquisa justifica-se pela relevante tendência de expansionismo que o marketing digital vem alcançando nas mídias sociais. O marketing digital abrange todas as áreas de mercado, em especial o setor do comércio. Dessa forma, entender a funcionalidade do marketing digital faz com que essa ferramenta seja aliada do comerciante em busca da fidelização do consumidor. Os dados obtidos através desta pesquisa poderão contribuir para se tenha uma melhor visão externa do que ocorre com as práticas do marketing digital colaborando de maneira significativa na aplicação das estratégias, beneficiando as futuras pesquisas na área.

\section{REVISÃO DE LITERATURA}

\subsection{MARKETING DIGITAL}

Para Dias (2006), o marketing é conceituado como uma função, que cria continuamente valor para o cliente e gera vantagem competitiva duradoura para a empresa, por meio da gestão estratégica das variáveis controláveis de marketing, também conhecido como Mix de Marketing. Dentre as várias formas de marketing, o marketing digital é de grande valia para as empresas que fazem uso das mídias sociais, uma vez que buscam promover seus produtos e manter estreita relação com seus clientes.

O marketing digital é um processo destinado a promover a venda de produtos e serviços a um determinado público-alvo usuário de internet e de sistemas de 
informação on-line, junto com ferramentas e serviços on-line, de forma estratégica e coerente com o programa de marketing da empresa (CINTRA, 2010).

Segundo Torres (2010), o marketing digital é o conjunto de estratégias de marketing e publicidade, aplicadas a Internet e ao novo comportamento do consumidor quando está navegando. Cintra (2010), afirma ainda que esta ferramenta tem se mostrado eficaz em muitos negócios, tanto para aqueles totalmente on-line, quanto para os que se utilizam de múltiplas plataformas de atendimentos, cruzando o varejo físico com a loja virtual.

Diante disso, é importante que a empresa que usa o marketing digital seja conhecedora das estratégias que essa ferramenta possa oferecer e, por conseguinte, aumentar o número de consumidores, reduzindo os custos e aumentando os lucros.

\subsection{ESTRATÉGIA DE MARKETING DIGITAL}

Estratégia é a definição de como os recursos será alocados para se atingir determinado objetivo, é uma disciplina que originalmente utilizada na área militar e, gradativamente, foi passando para as áreas de negócio (GABRIEL, 2010).

Conforme Torres (2009), várias estratégias de marketing digital, que servem de suporte para que as empresas possam criar uma presença forte na Internet, relacionar-se com seus consumidores conquistando novos clientes e mantendo satisfeitos os atuais. Dentre as estratégias apontadas pelo autor supracitado, destacam-se neste estudo: marketing nas mídias sociais e marketing de conteúdo.

De acordo com Torres (2010), o marketing nas mídias sociais é o conjunto de ações de marketing digital, que visam criar relacionamento entre a empresa e o consumidor, para atrair a sua atenção e conquistar o consumidor on-line, afirmando ainda que, o conteúdo gerado no marketing de conteúdo, é peça chave desse processo. As mídias sociais consistem de relacionamentos contínuos e duradouros entre pessoas e as comunidades onde elas integram (TORRES, 2009). 
Para o mesmo autor, algumas ações práticas devem ser observadas para que as empresas se relacionem efetivamente com seus clientes, sendo elas: criação de blogs, Twitters, listagem dos principais blogs que falam sobre temas relacionados ao seu negócio (mapa da blogosfera), criação de perfis nas redes sociais para interação com seus clientes, respondendo quando perguntado e criando ações promocionais simples, fáceis de entender com regras claras.

Um dos desafios utilizados pelas empresas que se utilizam do marketing digital para promover serviços e vendas de produtos é a promoção de conteúdos relevantes de interesse do público-alvo on-line.

Torres (2010), define marketing de conteúdo como sendo o conjunto de ações de marketing digital que visam produzir e divulgar conteúdo útil e relevante na Internet para atrair a atenção e conquistar o consumidor on-line, e sugere em seu "Guia Prático de Marketing na Internet para Pequenas Empresas" ações a serem seguidas na busca de sucesso do marketing de conteúdo, as quais encontram-se sumarizados a baixo:

a) Defina seu público-alvo, de forma clara e específica - Antes de qualquer ação é preciso pensar a respeito de quem se quer atingir, quem irá querer seu produto, entre outras palavras seu público-alvo.

b) Planeje o conteúdo - O produto deve ser planejado para o público-alvo, por isso pesquisas devem ser realizadas para saber suas reais necessidades e desejos para que o produto seja feito para atendê-las.

c) Não pense em produtos ou serviços, pense em informações úteis - Coloque-se no lugar do seu cliente e pense o que poderia está passando pela cabeça dele quando estivesse buscando um produto ou serviço que empresas como a sua oferece. Existem alguns passos para planejar com clareza esse conteúdo respondendo os seguintes questionamentos: quem é o público-alvo; o que se pretende do público-alvo; como se comporta o público-alvo; que informação o público-alvo busca; que conteúdo produzir para o público-alvo; e como produzir esse conteúdo. 
d) Aloque recursos- Algo de suma importância para a produção de conteúdo da empresa é a alocação dos recursos. Um investimento necessário para a prática do planejamento produzindo conteúdo de maneira constante.

e) Crie seu blog- A criação de um blog permite a exibição do conteúdo produzido e frequentemente atualizado, a melhor maneira é ligar o blog ao seu site de forma que ele possa aparecer pertencendo ao mesmo domínio e as atualizações de blog ainda podem aparecer no site.

f) Divulgue- Use as mídias sociais tais como Facebook, Twitter entre outras para a divulgação do seu blog aproveitando todas as possibilidades de divulgações possíveis.

g) Conteúdo útil e relevante- A relevância do conteúdo é algo que sempre deve estar dentro da preocupação para que dessa forma mantenha sempre os clientes atualizados, mas de conteúdo útil e que seja relevante a seus clientes.

h) Foco é tudo- A função dos textos no blog é atrair clientes para o site, em decorrência disso leva-os a efetuar a compra de produtos ou serviços.

i) Monitore os resultados - "o marketing digital é feito para dar resultados" por isso a importância do monitoramento dos resultados periodicamente analisando o comportamento do consumidor com respeito as publicações.

\section{METODOLOGIA}

A pesquisa procedeu-se inicialmente com a revisão bibliográfica exploratória de livros, artigos e sites que abordam assuntos de interesse para este estudo e, posteriormente, realizou-se um estudo comparativo, sendo fundamentado por pesquisa descritiva com abordagem qualitativa e quantitativa, através de coletas diárias de dados por um período de 15 dias (1 a 15 de setembro de 2016) nas mídias sociais.

Duas empresas nordestinas, aqui identificadas por A e B para manter, desta forma, sigilo sobre elas foram selecionadas de acordo com os seguintes critérios em comum: 
setor de atividade (supermercado), empresa privada, volume de vendas, ano de fundação e por não possuírem lojas virtuais.

Para avaliar a aproximação entre cliente e empresa, foram selecionadas cinco mídias sociais (Facebook, Twitter, Instagram, Website e Blog), adotadas ou não pelas empresas, e buscou-se, a partir delas, analisar a relevância dos conteúdos publicados e indicadores de redes sociais, como pode se observar no quadro 1.

Quadro 1. Relação das redes sociais e seus respectivos indicadores.

\begin{tabular}{|l|l|}
\hline REDES SOCIAIS & INDICADORES \\
\hline Facebook & Número total de curtidas no perfil; Número total de posts. \\
\hline Twitter & Número total de tweets; Número total de followers. \\
\hline Instagram & Número total de posts; Número total de seguidores \\
\hline
\end{tabular}

Fonte: Próprio autor.

Os dados quantitativos das redes sociais Facebook, Twitter e Instagram foram validados através de pesquisa de campo na plataforma Fanpage Karma, uma ferramenta on-line gratuita, que fornece indicadores de desempenho dos perfis de mídia social.

Analisou-se também, as estratégias de marketing digital adotadas pelas empresas, tendo como parâmetro duas estratégias definidas por Torres (2009) em sua obra "A Bíblia do Marketing Digital", sendo elas: marketing nas mídias sociais e marketing de conteúdo.

\section{RESULTADOS E DISCUSSÃO}

\subsection{MARKETING NAS MÍDIAS SOCIAIS}

A partir da pesquisa on-line, em site de busca, constatou-se que as empresas pesquisadas A e B possuem mídias sociais tais como Facebook, Twitter, Instagram e Website, no entanto apenas a empresa B possuem Blog. A obtenção dos dados 
quantitativos deu-se mediante as coletas diárias dos dados de indicadores de redes sociais no período de duas semanas de observações dos perfis das empresas A e $B$ nas redes sociais Facebook, Twitter e Instagram.

Os dados quantitativos obtidos durante 15 dias de observações, seguidas de anotações, foram validados por meio da plataforma Fanpage Karma. Outros indicadores de desempenho, como por exemplo, a performance (índice de desempenho) dos perfis das empresas A e B nas mídias Facebook, Twitter e Instagram foram avaliados pela mesma plataforma.

\subsubsection{FACEBOOK}

Os dados quantitativos dos indicadores da rede social Facebook para as duas empresas estudadas encontram-se na tabela 1.

Tabela 1. Total de dados quantitativos dos indicadores da rede social Facebook: número de posts e curtidas na página.

\begin{tabular}{|c|c|c|c|c|c|c|}
\hline \multicolumn{7}{|l|}{ Facebook } \\
\hline \multirow{2}{*}{ Empresa } & \multicolumn{2}{|c|}{$1^{a}$ Semana } & \multicolumn{2}{|c|}{$2^{\text {a }}$ Semana } & \multicolumn{2}{|l|}{ Total } \\
\hline & $\begin{array}{l}\text { № total } \\
\text { de } \\
\text { posts }\end{array}$ & $\begin{array}{l}\text { № total de } \\
\text { curtidas no } \\
\text { perfil }\end{array}$ & $\begin{array}{l}\text { № total } \\
\text { de } \\
\text { posts }\end{array}$ & $\begin{array}{l}\text { № total de } \\
\text { curtidas no } \\
\text { perfil }\end{array}$ & $\begin{array}{l}\text { № total } \\
\text { de } \\
\text { posts }\end{array}$ & $\begin{array}{l}\text { № total de } \\
\text { curtidas no } \\
\text { perfil }\end{array}$ \\
\hline A & 44 & 20 & 54 & 32 & 98 & 52 \\
\hline B & 18 & 5132 & 16 & 4429 & 34 & 9561 \\
\hline Média & 31 & 2576 & 35 & 2231 & 66 & 4807 \\
\hline
\end{tabular}

Fonte: Elaborada pelo autor.

$\mathrm{Na}$ primeira semana de observações, a empresa A obteve um total de 44 posts acrescidos de 20 curtidas no perfil, é o que se observa na tabela acima havendo aumento na segunda semana de 54 posts e 32 curtidas no perfil, considerando as duas semanas, a empresa A obteve um total de 98 posts e 52 curtidas no perfil, já a empresa $B$, na primeira semana obteve um total de 18 posts acrescidos de 5.132 
curtidas no perfil, tendo um decréscimo na segunda semana no número de posts e curtidas no perfil, 16 e 4.429 respectivamente. Considerando as duas semanas, a empresa B obteve um total de 34 posts e 9.561 curtidas no perfil.

Comparando a dinâmica dos números totais de posts e curtidas nas duas semanas de observações para os perfis das empresas A e B no Facebook, constata-se que a primeira, apesar de ter maior número de posts, não conquistou tanta curtida comparada com a segunda que, apesar de ter menor número de posts, conquistou maior número de curtidas. Desta forma, podemos deduzir que os conteúdos gerados pela empresa $B$ nas duas semanas de observações foram mais interessantes para os usuários.

Segundo Gollner e Goulart (2012), "a funcionalidade 'Curtir' representa uma métrica para avaliar a estratégia de comunicação digital corporativa no Facebook, e afirma ainda que o resultado em números de 'Curtir', que pode se revelar para cada postagem, é uma resposta positiva do usuário à atuação da empresa na plataforma."

Através da plataforma Fanpage Karma verificou-se que os perfis das empresas A e B no Facebook até a data final deste estudo (15 de setembro de 2016) verificar- se o estudo ocorreu nessa data, apresentaram respectivamente: índice de desempenho de 35\% e 100\%; 27 e 3,0K números de comentários; 18k e 52k números de seguidores; $1.1 \mathrm{~K}$ e $8,3 \mathrm{~K}$ números de curtidas, sendo os dois últimos indicadores valores totais somados desde a criação do perfil até a data final desta pesquisa (Figura 1). 
Figura 1. Indicadores de desempenho do perfil das empresas A e B no Facebook durante 1 a 15 de setembro de 2016.

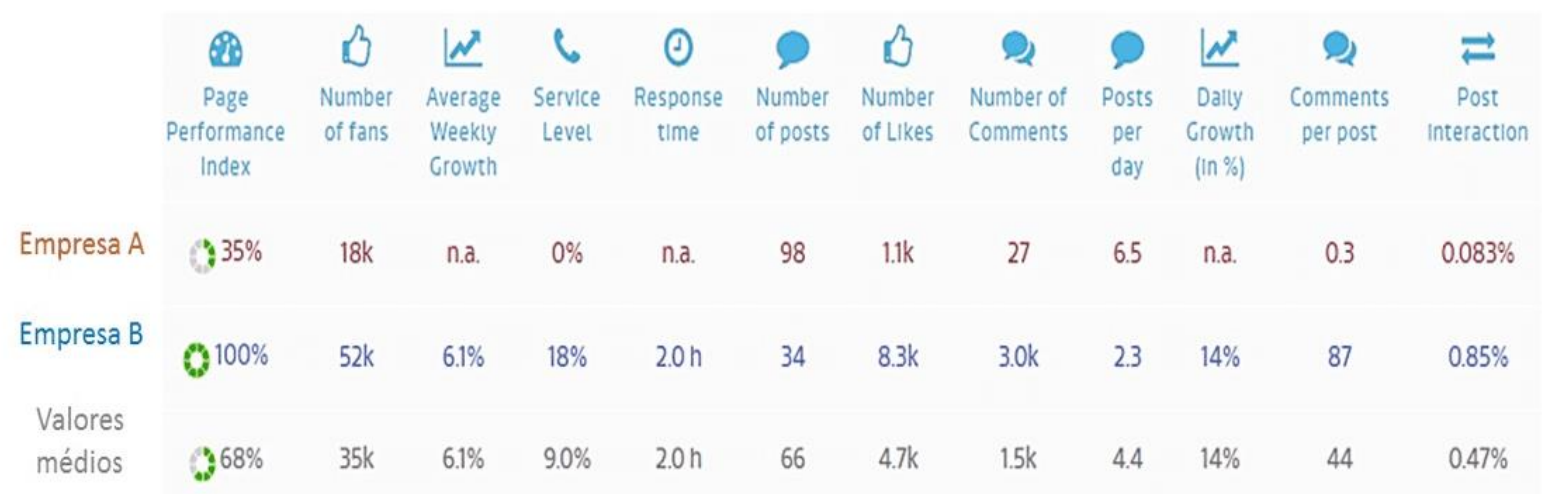

Fonte: http://www.fanpagekarma.com.

O perfil da empresa $B$ no Facebook possui uma frequência de postagens menor em relação ao perfil da empresa $A$, que possui frequência de mensagens por dia de 6,5 , enquanto o perfil da empresa B possui apenas 2,3, todavia a primeira se destaca nos demais indicadores de desempenho.

Ainda sobre os dados quantitativos analisados diretamente no perfil até a data 15 de setembro de 2016, revelaram que o perfil da empresa $A$ atingiu um total de 137 visualizações em sua página e conquistou 3,8 estrelas, porém o perfil da empresa $B$, obteve valores evidentemente maiores para visualizações como para o número de estrelas, 147 e 4,4, respectivamente.

\subsubsection{TWITTER}

Os dados quantitativos dos indicadores de rede social Twitter para as duas empresas analisadas encontram-se na tabela 2.

Tabela 2. Total de dados quantitativos dos incadores da rede social Twitter: número de tweets e followers.

Twitter

\begin{tabular}{l|l|l|l} 
Empresa & $1^{\text {a }}$ Semana & $2^{\text {a Semana }}$ & Total
\end{tabular}




\begin{tabular}{|l|l|l|l|l|l|l|}
\hline & $\begin{array}{l}\text { № total } \\
\text { de } \\
\text { tweets }\end{array}$ & $\begin{array}{l}\text { № total } \\
\text { followers }\end{array}$ & $\begin{array}{l}\text { № total } \\
\text { de }\end{array}$ & $\begin{array}{l}\text { № total } \\
\text { followers }\end{array}$ & $\begin{array}{l}\text { № total } \\
\text { tweets }\end{array}$ & $\begin{array}{l}\text { № total } \\
\text { followers } \\
\text { tweets }\end{array}$ \\
\hline A & 0 & 2 & 0 & 1 & 0 & 3 \\
\hline B & 2 & 9 & 1 & 17 & 3 & 26 \\
\hline Média & $\mathbf{1}$ & $\mathbf{6 , 5}$ & $\mathbf{0 , 5}$ & $\mathbf{9}$ & $\mathbf{1 , 5}$ & $\mathbf{1 4 , 5}$ \\
\hline
\end{tabular}

Fonte: Elaborada pelo autor.

Tanto na primeira como segunda semana, a empresa A não fez posts em seu perfil, e chegou ao final das duas semanas com apenas 3 novos followers, diferentemente a empresa B publicou 2 tweets na primeira semana e obteve 9 novos followers e, na segunda semana, publicou 1 tweet e obteve 17 novos followers, considreando duas semanas, a empresa B obteve um total de 3 Tweets e 26 novos followers.

Pela plataforma Fanpage Karma, percebe-se que os perfis de ambas as empresas na mídia social Twitter não diferem quanto ao índice de desempenho, sendo esse valor igual a 8,0\%, e não obtiveram crescimento médio semanal e com relação aos demais indicadores de desempenho, as empresas A e B obtiveram, respectivamente: 0 e 0,3 número de likes por tweet; $1,2 \mathrm{~K}$ e 2,6K número total de seguidores somados desde a criação do perfil até a data final desta pesquisa (Figura 2). 
Figura 2. Indicadores de desempenho do perfil das empresas A e B no Twitter durante 1 a 15 de setembro de 2016.

\begin{tabular}{|c|c|c|c|c|c|c|c|}
\hline & 8 & $N$ & $\rho$ & ○ & $y$ & 0 & Q \\
\hline & $\begin{array}{l}\text { Profile Performance } \\
\text { Index }\end{array}$ & $\begin{array}{l}\text { Average } \\
\text { Weekly } \\
\text { Crowth }\end{array}$ & Tweets & Tweets/day & Follower & $\begin{array}{l}\text { Number of } \\
\text { llkes per } \\
\text { tweet }\end{array}$ & Conversations \\
\hline Empresa A & $8.0 \%$ & n.a. & 0 & 0 & $1.2 \mathrm{k}$ & 0 & $0 \%$ \\
\hline Empresa B & $8.0 \%$ & ก.a. & 3 & 0.2 & $2.6 \mathrm{k}$ & 0.3 & $100 \%$ \\
\hline $\begin{array}{l}\text { Valores } \\
\text { médios }\end{array}$ & $8.0 \%$ & n.a. & 2 & 0.1 & $1.9 \mathrm{k}$ & 0.2 & $50 \%$ \\
\hline
\end{tabular}

Fonte: http://www.fanpagekarma.com.

É notório que, as duas empresas apesar de terem perfis na mídia Twitter não utilizam essa ferramenta de forma ativa, influenciando, desta forma, na conquista de novos followers, sendo a frequência de tweets por dia no perfil das empresas $\mathrm{A}$ e $\mathrm{B}$ de $0 \mathrm{e}$ 0,2 , respectivamente, valores esses considerados baixos para ambas as empresas.

Um ponto positivo observado no perfil da empresa B, é que a mesma, apesar de pouco utilizar a ferramenta Twitter, possui uma alta interação com seus seguidores, $100 \%$, enquanto na empresa $A$, esse indicador de desempenho foi $0 \%$.

Gonçalves (2012), destaca a mídia social Twitter como um instrumento em que as empresas possam interagir diretamente com seus clientes, e nele o cliente tem a liberdade de expor suas opiniões, se posicionar através de críticas e elogiar determinado produto ou serviço. Portanto, cabe às empresas, objetos deste estudo, reconhecerem o Twitter como uma excelente ferramenta de estratégia de marketing digital, fazendo o bom uso e tirando maior proveito de suas vantagens, sendo uma delas, o seu baixo custo. 


\subsubsection{INSTAGRAM}

Através dos dados quantitativos de indicadores da rede social Instagram, verificou-se que a empresa $A$, na primeira semana de observação, atingiu um total de 51 posts e ganhou 20 novos seguidores, já na segunda semana fez 52 posts ganhando 25 novos seguidores, já a empresa $B$, na primeira semana, atingiu um total de 16 posts e ganhou 81 novos seguidores e, na segunda semana, fez apenas 10 posts e ganhando mais 77 novos seguidores, evidentemente, diminuiu seu número de publicações, como pode constatar na tabela 3.

Tabela 3. Total de dados quantitativos dos indicadores da rede social Instagram: número de posts e seguidores.

\begin{tabular}{|c|c|c|c|c|c|c|}
\hline \multicolumn{7}{|l|}{ Instagram } \\
\hline \multirow[t]{2}{*}{ Empresa } & \multicolumn{2}{|c|}{ 1a Semana } & \multicolumn{2}{|c|}{2 a Semana } & \multicolumn{2}{|l|}{ Total } \\
\hline & $\begin{array}{l}\text { № total } \\
\text { de } \\
\text { posts }\end{array}$ & $\begin{array}{l}\text { № total } \\
\text { seguidores }\end{array}$ & $\begin{array}{l}\text { № total } \\
\text { de } \\
\text { posts }\end{array}$ & $\begin{array}{l}\text { № total } \\
\text { seguidores }\end{array}$ & $\begin{array}{l}\text { № total } \\
\text { de } \\
\text { posts }\end{array}$ & $\begin{array}{l}\text { № total } \\
\text { seguidores }\end{array}$ \\
\hline A & 51 & 20 & 52 & 25 & 103 & 45 \\
\hline$B$ & 16 & 81 & 10 & 77 & 26 & 158 \\
\hline Média & 33,5 & 50,5 & 31 & 51 & 65 & 101,5 \\
\hline
\end{tabular}

Fonte: Elaborada pelo autor.

Comparando os perfis das empresas A e B na mídia, a segunda leva vantagens com relação ao número total de novos seguidores nas duas semanas de interatividade, sendo esse valor total igual 158, mesmo mantendo um número de posts baixo nas duas semanas, sendo ao todo apenas 26 posts. Valores contrastantes foram evidentes no perfil da empresa $\mathrm{A}$, que obteve um número alto de posts sendo 103 , porém baixo número total de novos seguidores 45 .

Essa diferença discrepante no total de novos seguidores analisados em ambos os perfis, pode ser justificado pelo fato da empresa B, apesar de fazer poucos posts, usou 
melhor a estratégia de marketing na rede social, o que resultou na conquista de novos seguidores, e concomitantemente, estreitando a aproximação com seus clientes.

Em relação à plataforma Fanpage Karma, constata-se que o índice de desempenho do perfil da empresa B no Instagram foi de $36 \%$, sendo esse valor superior ao perfil da empresa $A$, que foi $22 \%$, com relação aos demais indicadores de desempenho, as empresas A e B obtiveram, respectivamente: 18 e 81 números de comentários; 0,2 e 3,1 comentários por posts (Figura 3).

Figura 3. Indicadores de desempenho do Instagram das empresas A e B durante 1 a 15 de setembro de 2016.

\begin{tabular}{|c|c|c|c|c|c|c|c|}
\hline & $\underset{\text { Follower }}{8}$ & $\underset{\text { Following }}{8}$ & $\begin{array}{l}\text { Number of } \\
\text { Posts }\end{array}$ & $\overbrace{\text { comments }}$ & $\begin{array}{l}\text { Posts per } \\
\text { day }\end{array}$ & $\begin{array}{l}\text { Profile Performance } \\
\text { Index }\end{array}$ & $\overbrace{\substack{\text { Comments per } \\
\text { post }}}$ \\
\hline Empresa A & $3.2 \mathrm{k}$ & 4.4k & 103 & 18 & 6.9 & $22 \%$ & 0.2 \\
\hline Empresa B & $2.5 \mathrm{k}$ & $1.5 \mathrm{k}$ & 26 & 81 & 1.7 & $36 \%$ & 3.1 \\
\hline $\begin{array}{l}\text { Valores } \\
\text { médios }\end{array}$ & $2.9 \mathrm{k}$ & $2.9 \mathrm{k}$ & 65 & 50 & 4.3 & $29 \%$ & 1.6 \\
\hline
\end{tabular}

Fonte: http://www.fanpagekarma.com.

A empresa $\mathrm{A}$, no total, até a data final desta pesquisa, tem 3,2K número de seguidores em seu perfil, valor esse, que supera o número de seguidores no perfil da empresa $B$, que é de apenas 2,5K, sendo que a última criou seu perfil no Instagram 2 anos mais tarde, e mesmo assim, levou vantagem com relação ao número total de seguidores. Curiosamente, a empresa $B$, também leva vantagens com relação ao número de likes, que é 1,8K, diferente da empresa $\mathrm{A}$, que só tem 927 likes.

Mediante análise do perfil da empresa A na mídia, constatou-se que a mesma possui baixa interatividade e não publica conteúdos relevantes para atingir seu público-alvo, e isso tem refletido negativamente no número de likes. 


\subsubsection{WEBSITE}

Notadamente, as duas empresas exibem em seus websites página inicial similar e média personalização. A empresa B possui em seu website ícones de direcionamento para as redes sociais Facebook, Twitter e Instagram e vice-versa, diferentemente, o blog fica disponível na guia da página. A empresa A possui ícones para o direcionamento apenas para as redes sociais Facebook e Twitter, e vice-versa.

O ideal seria o website da empresa linkar suas demais mídias sociais, e as mesmas linkarem para o website, o que de fato não se observa na empresa $A$, que possui link do website na mídia Instagram, porém, o contrário é inexistente.

Ambas as empresas não geram diariamente ou com frequência conteúdos no website sendo, desta forma o fluxo de informações considerado baixo, quando comparado com as mídias sociais Facebook e Instagram onde fluxo de informações é maior.

\subsubsection{BLOG}

Telles (2009), defende que os blogs são essenciais como ferramentas corporativas, no sentido de promover marcas e melhorar a comunicação entre empresa e seus clientes.

Como foi visto, apenas a empresa B usa a mídia social blog, sendo que ele fica acessível na guia de seu website, exibindo com pouca frequência conteúdos atualizados. Estrategicamente, o fluxo de informações veiculadas no blog apareça simultaneamente no website. Nota-se que a estratégia acima é condizente com as ideias de Torres (2010), e se faz presente na estratégia de marketing de conteúdo.

\subsection{MARKETING DE CONTEÚDO}

Acompanhou-se o fluxo de informações nas mídias sociais onde as empresas possuem perfis, bem como o design das páginas e avaliou-se a estratégia de marketing de conteúdo adotada por ambas para atingir seu público-alvo. 
As duas empresas possuem design similar na mídia Facebook e até a data desta pesquisa, ambas as empresas exibem em suas páginas a imagem da capa com informações sobre o aniversário de 30 anos, e foto de perfil com suas respectivas logomarcas. É válido destacar que, o design das páginas nas mídias sociais é de importância, já que o objetivo inicial de qualquer empresa foi de chamar a atenção do visitante, e desta forma possa atraí-lo.

Quanto ao fluxo de informações das mídias (Facebook, Instagram e website), a empresa A posta com frequência conteúdos sobre preços, produtos, promoções e ofertas, logo, percebe-se que a maioria dos conteúdos é de comunicação inteiramente mercadológico e raramente relacional.

Por outro lado, a empresa B para as mesmas mídias analisada, nunca posta conteúdos sobre preços e promoções, porém utiliza suas mídias para divulgar produtos e marcas que se faz de forma dinâmica e humorada, no sentido de despertar a atenção do usuário e persuadi-lo a buscar pelos produtos e serviços em suas lojas físicas. Sendo assim, o perfil da empresa B tem como pontos fortes em seus conteúdos, a comunicação relacional e institucional, sendo essa estratégia importante para aproximar cliente e empresa.

Como mencionado anteriormente, ambas as empresas possuem baixo desempenho na mídia Twitter, onde raramente fazem publicações, porém quando as fazem, seus conteúdos são inteiramente dinâmicos e humorados. Analisando os conteúdos de modo geral, percebe-se que a empresa A posta, na maior parte, informações contendo dicas de saúde com base na alimentação, e a empresa $B$, na maior parte, convida o leitor a visitar suas lojas físicas. Não foram encontradas publicações com divulgação de preços, produtos e promoções em ambos os perfis analisados.

Segundo Gonçalves (2012), "é necessário sempre manter o Twitter da organização atualizado, com conteúdo interessante, que deixe seus clientes atraídos, o que os torna uma marca forte na memória de seus consumidores". Nesse contexto, acreditase que as empresas, apesar de postarem conteúdos interessantes, não mantêm o 
Twitter atualizado, repercutindo na diminuição drástica da interação com seus consumidores.

A empresa B posta, com pouca frequência, conteúdos variados em seu blog, sendo que sua primeira postagem foi na data 13 de julho de 2016. Os conteúdos que veiculam em sua página são: receitas de culinárias, vagas de emprego, patrocínios, novidades sobre produtos e serviços, entre outros. Por fim, não foram encontradas publicações que se destinam a divulgar preços de produtos.

\section{CONSIDERAÇÕES FINAIS}

O presente trabalho, realizado entre duas empresas de supermercados, buscou analisar a relação que elas têm com seus clientes nas mídias sociais utilizando-se do marketing digital como instrumento para este processo, pois levando em consideração a modernização contínua do mercado essa ferramenta está sendo cada vez mais adotada por empresas para que então possa estreitar a relação com seus clientes e divulgar marcas, preços e produtos/serviços. Essa prática se dá devida à alta praticidade e de baixo custo que tem o marketing digital.

Durante o período de 15 dias as redes sociais Facebook, Twitter e Instagram, foram observadas em suas publicações e a relevância, a reação de seus seguidores através das funções curtir, comentar e compartilhar e quantos seguidores adquiriam no decorrer de cada dia. Por intermédio da plataforma Fanpage Karma, foi possível fazer uma análise mais elaborada dos dados quantitativos que se apresentava em porcentagens de maneira explícita sobre seus indicadores de desempenho.

Uma situação que não foi possível de ser observada nas redes sociais, foi à quantidade de seguidores que as empresas perdiam nesse tempo de observação, uma vez que as redes sociais só permitem acesso a determinadas informações às proprietárias dos perfis em ferramentas próprias com finalidade de poderem fazer análise do seu desempenho. 
A aplicação marketing de conteúdo e o marketing digital, utilizado por essas duas empresas foi analisado para observar o poder de seu alcance e, consequentemente refletido na interação dos clientes para com as mesmas. Através das observações foi possível constatar que as empresas $A$ e $B$ são mais ativas nas mídias sociais Facebook e Instagram, onde também mais se viu a aplicação dessas ferramentas. A empresa $B$ leva vantagens com relação ao número de usuários em todas as redes sociais analisadas e, também, foi à única que adotou o blog como estratégia de marketing em mídias sociais.

Com relação ao conteúdo postado pelas empresas, os resultados são claramente refletidos nos desempenhos que alcançam com o trabalho que desempenham. $\mathrm{Na}$ empresa A seus conteúdos são, em sua maioria, ligados apenas a expor preços de produtos e promoções do dia, poucas vezes se posta algo institucional e nunca se postou algo relacional tornando assim 0 perfil monótono deixando-os desinteressantes. A empresa B, como se pode observar, posta maior parte dos seus conteúdos nas mídias sociais com intenção inteiramente relacional, uma forma criativa de expor seus produtos com suas funcionalidades, e institucional, o que leva a concluir que sua forma de fazer marketing digita é a mais eficaz sendo a referida empresa a que apresentou maior engajamento e aproximação com seus clientes.

\section{REFERÊNCIAS}

BARICHELLO, E. M. M. R.; OLIVEIRA, C. C. O. Marketing viral como estratégia publicitária nas novas ambiências midiáticas. Em Questão, Porto Alegre, v.16, n.1, p.29-44, 2010. Disponível em: https://seer.ufrgs.br/EmQuestao/article/view/12939. Acesso em: 19 de outubro de 2016.

BOGO, R. H.; KLOCH, I. Marketing digital. 2012. Disponível em: https://docplayer.com.br/18300425-Marketing-digital-maieutica-curso-de-processosgerenciais.html. Acesso em: 19 de outubro de 2016.

CINTRA, F. C. Marketing Digital: A era da tecnologia on-line. Investigação, v.10, n.1, p.6-12, $2010 . \quad$ Disponível em: 
http://publicacoes.unifran.br/index.php/investigacao/article/view/147. Acesso em: 25 de outubro de 2016.

DIAS, S. R. Gestão de Marketing. 1.ed. São Paulo: Saraiva, 2006.

GABRIEL, M. Marketing na era digital: conceitos, plataformas e estratégias. 1.ed. São Paulo: Novatec, 2010.

GOLLNER, A. P.; GOULART, E. E. Curtindo a mensagem corporativa: novos tempos na comunicação organizacional. In: XXXV CONGRESSO BRASILEIRO DE CIÊNCIAS DA COMUNICAÇÃO, 2012, Fortaleza. Anais Eletrônicos. Fortaleza-CE, 2012. Disponível em: http://www.intercom.org.br/sis/2012/resumos/R7-1097-1.pdf. Acesso em: 04 de setembro de 2016.

GONÇALVES, J. S. Twitter como ferramenta de marketing: um estudo sobre a rede social nas empresas da cidade de Picos-PI. 2012. 46f. Monografia (Bacharelado em Administração) - Universidade Federal do Piauí, Picos-PI, 2012.

TELLES, A. Geração digital: como planejar o seu marketing para geração que pesquisa Google, se relaciona no Orkut, manda mensagens pelo celular, opina em blogs, se comunica pelo MSN e assisti VID. 1.ed. São Paulo: Editora Landscape, 2009.

TORRES, C. Guia prático de marketing na internet para pequenas empresas. 2010.

Disponível em:https://www.cairu.br/biblioteca/arquivos/Marketing/Marketing_Internet_TORRES. pdf. Acesso em: 04 de setembro de 2016.

A bíblia do marketing digital: tudo o que você queria saber sobre marketing e publicidade na internet e não tinha a quem perguntar. 1.ed. São PauloSP: Novatec, 2009.

Enviado: Setembro, 2019.

Aprovado: Novembro, 2019. 